\title{
A Variant of the Autophagy-Related 5 Gene Is Associated with Child Cerebral Palsy
}

\begin{abstract}
Jianhua $\mathrm{Xu}^{1+}$, Lei Xia ${ }^{2 \dagger}$, Qing Shang ${ }^{3}$, Jing $\mathrm{Du}{ }^{1}$, Dengna $\mathrm{Zhu}^{2,4}$, Yangong Wang ${ }^{1}$, Dan $\mathrm{Bi}^{2}$, Juan Song ${ }^{2}$, Caiyun $\mathrm{Ma}^{3}$, Chao Gao ${ }^{3}$, Xiaoli Zhang ${ }^{2}$, Yanyan Sun ${ }^{2}$, Liping Zhu ${ }^{5}$, Xiaoyang Wang ${ }^{6}$, Changlian $\mathrm{Zhu}^{2,7 *}$ and Qinghe Xing ${ }^{1,5 *}$

${ }^{1}$ Institute of Biomedical Science and Children's Hospital, and Key Laboratory of Reproduction Regulation of the National Population and Family Planning Commission (NPFPC), Shanghai Institute of Planned Parenthood Research (SIPPR), IRD, Fudan University, Shanghai, China, ${ }^{2}$ Henan Key Laboratory of Child Brain Injury, Department of Pediatrics, The 3rd Affiliated Hospital of Zhengzhou University, Zhengzhou, China, ${ }^{3}$ Department of Pediatrics, Henan Children's Hospital, Zhengzhou, China, ${ }^{4}$ Child Rehabilitation Center, The 3rd Affiliated Hospital of Zhengzhou University, Zhengzhou, China, ${ }^{5}$ Shanghai Center for Women and Children's Health, Shanghai, China, ${ }^{6}$ Perinatal Center, Sahlgrenska Academy, Gothenburg University, Gothenburg, Sweden, ${ }^{7}$ Center for Brain Repair and Rehabilitation, Sahlgrenska Academy, Gothenburg University, Gothenburg, Sweden
\end{abstract}

Cerebral palsy (CP) is a major cause of childhood disability in developed and developing countries, but the pathogenic mechanisms of CP development remain largely unknown. Autophagy is a highly conserved cellular self-digestion of damaged organelles and dysfunctional macromolecules. Growing evidence suggests that autophagy-related gene 5 (ATG5)-dependent autophagy is involved in neural development, neuronal differentiation, and neurological degenerative diseases. The aim of this study was to analyze ATG5 protein expression and gene polymorphisms in Chinese patients with CP and to evaluate the importance of ATG5 in the development of CP. Five polymorphisms from different regions of the ATG5 gene (rs510432, rs3804338, rs573775, rs2299863, and rs6568431) were analyzed in 715 CP patients and 658 controls using MassARRAY. Of these, 58 patients and 56 controls were selected for measurement of plasma ATG5 level using ELISA. The relevance of disease-associated SNPs was evaluated using the SHEsis program. We identified a significant association between rs6568431 and CP $\left(\mathrm{OR}=1.388,95 \% \mathrm{Cl}=1.173 \sim 1.643, P_{\text {allele }}=0.0005, P_{\text {genotype }}=0.0015\right)$. Subgroup analysis showed a highly significant association of $r 56568431$ with spastic $C P(n=468$, $\left.\mathrm{OR}=1.511,95 \% \mathrm{Cl}=1.251 \sim 1.824, P_{\text {allele }}=8.50 \mathrm{e}^{-005}, P_{\text {genotype }}=1.57 \mathrm{e}^{-004}\right)$ and spastic quadriplegia $\left(\mathrm{OR}=1.927,95 \% \mathrm{Cl}=1.533 \sim 2.421, P_{\text {allele }}=7.35 \mathrm{e}^{-008}, P_{\text {genotype }}\right.$ $\left.=3.24 \mathrm{e}^{-009}\right)$. Furthermore, mean plasma ATG5 levels were lower in CP patients than in controls, and individuals carrying the AA genotype of rs6568431 that was positively associated with CP had lower plasma ATG5 levels $(P<0.05)$. This study demonstrated an association of an ATG5 gene variant and low level of ATG5 protein with CP, and stronger associations with severe clinical manifestations were identified. Our results provide novel evidence for a role of ATG5 in CP and shed light on the molecular mechanisms underlying this neurodevelopmental disorder.

Keywords: ATG5, autophagy, cerebral palsy, ELISA, polymorphisms, single nucleotide 


\section{INTRODUCTION}

Cerebral palsy (CP) is a group of permanent developmental disorders of movement and posture that appear in early childhood, often accompanied by epilepsy and disturbances in perception, sensation, cognition, behavior, and communication, as well as secondary musculoskeletal problems (Colver et al., 2014; Hoare, 2014). CP can cause activity limitation due to nonprogressive disturbances in the developing fetal or infant brain (Colver et al., 2014). Though antenatal and perinatal care have improved, overall prevalence has remained stable at 2-3.5 cases per 1,000 live births in the past 40 years (Yeargin-Allsopp et al., 2008; Colver et al., 2014). CP is a major cause of childhood disability in developed and developing countries ( $\mathrm{Wu}$ et al., 2011; Tatla et al., 2013), but the underlying pathogenic factors and molecular mechanisms for the development of $\mathrm{CP}$ remain largely unknown. Some recent studies have connected many cases of $\mathrm{CP}$ to genetic alterations that may directly cause or confer susceptibility to CP (McMichael et al., 2015; Bi et al., 2016; Fahey et al., 2017).

Autophagy is a highly regulated process involving the degradation of unused macromolecules and damaged cell organelles in the cytosol through the lysosomal system (Shintani and Klionsky, 2004; De Biase et al., 2017). Three forms of autophagy are commonly described: macroautophagy, microautophagy, and chaperone-mediated autophagy. In macroautophagy, targeted cytoplasmic constituents are isolated from the rest of the cell within a double-membraned vesicle known as an autophagosome. The autophagosome eventually fuses with lysosomes and the contents are degraded and recycled (Mizushima et al., 2011). Autophagy is involved in many physiological processes, including development, differentiation, aging, innate immunity, quality control of intracellular proteins and organelles, starvation adaptation, and tumor suppression (Oppenheim et al., 2008; Tasdemir et al., 2008; Wang et al., 2017). Furthermore, dysregulated autophagy has been implicated in inflammatory and neurodegenerative diseases (Levine and Kroemer, 2008; Wong and Cuervo, 2010; Deretic et al., 2013).

Autophagy-related gene 5 (ATG5), a key autophagy gene, contributes to autophagosome formation, and its deletion can effectively block autophagy in yeast, mammal cells, or mice (Kuma et al., 2004). In this process, ATG12, activated first by ATG7, is transferred to ATG10, and finally covalently attached to ATG5. The ATG12-ATG5 conjugate localizes to autophagosome precursors and dissociates just before or after completion of autophagic-vacuole formation (Mizushima et al., 2003, 2011). Furthermore, ATG5 may have its own autophagy-independent functions, i.e., isolated ATG functions, which involve genespecific function instead of effectuation of the integral autophagy pathway. For instance, the ATG5-ATG12 conjugate acts as a suppressor of retinoic acid-inducible gene 1-like receptor (RLR) signaling (Jounai et al., 2007; Tal et al., 2009; Zhou and Zhang, 2012), ATG5 has macroautophagy-independent roles in controlling resistance to Mycobacterium tuberculosis (Mtb) infection in vivo (Jacqueline et al., 2015), and Atg5 protein participates in immunity and intracellular killing of pathogens via autophagosome-independent processes in phagocytic cells (Zhao et al., 2008).

Mice deficient in ATG5 die within 1 day of delivery (Kuma et al., 2004), while mice with specific deletion of ATG5 in neural cells can develop gradual defects in motor function accompanied by the accumulation of cytoplasmic inclusion bodies in neurons (Hara et al., 2006). ATG5 loss in Purkinje cells causes the cells to degenerate and animals to exhibit ataxic gait (Nishiyama et al., 2007). Elevated ATG5 expression, on the other hand, interferes with the neuronal differentiation of neuroblastoma cells (Chae et al., 2009), and ATG5 has been shown to function during early neuronal differentiation of stem and progenitor cells (Vázquez et al., 2012). Together, these data indicate that ATG5 is involved in neural development, neuronal differentiation, and neurological degenerative diseases.

Recent studies have shown that genetic variants of ATG5 play a role in predisposition to various neurodegenerative diseases such as Parkinson's disease (PD; Chen et al., 2013), autoimmune diseases such as systemic lupus erythematosus (SLE; López et al., 2013), and inflammatory diseases such as asthma (Martin et al., 2012). Although ATG5 is increasingly recognized for its involvement in the pathogenesis of $\mathrm{CP}$, the association of ATG5 genetic variants with $\mathrm{CP}$ has not yet been investigated. Therefore, we analyzed five single nucleotide polymorphisms (SNPs) from different regions of the ATG5 gene in 715 patients with CP and 658 controls. Furthermore, we used a plasma ATG5 protein assay to clarify the functional association of ATG5 polymorphisms and $\mathrm{CP}$, based on the reports that some polymorphisms within ATG5 correlated with ATG5 expression (Zhou and Zhang, 2012; Zheng et al., 2015).

\section{MATERIALS AND METHODS}

\section{Study Subjects}

A total of 715 patients with CP (30.63\% girls and $69.37 \%$ boys, mean age: $18.26 \pm 15.13$ months old) were recruited from centers for CP rehabilitation in the 3rd Affiliated Hospital of Zhengzhou University and Henan Children's Hospital from July 1, 2010 to May 31, 2014. Another 658 controls (33.43\% girls and 66.57\% boys, mean age: $19.53 \pm 17.18$ months old) were chosen from a physical examination population from the same hospital during the same time period. Of these, 58 patients with CP (38 boys and 20 girls, $20.54 \pm 13.13$ months old) and 56 controls (42 boys and 14 girls, $21.95 \pm 14.65$ months old) were selected for plasma ATG5 ELISA based on the strict exclusion criteria. First, all children with cough, fever, acute respiratory illness, any other indications of infection, or dramatic changes of bodyweight within the past 3 months were excluded. Second, the CP patients who have received any other medication within 1 month were excluded. All recruited children were from the Han population of the Henan Province, and their parents were asked to sign informed consent. Approval for the study was obtained from the ethics committee of Zhengzhou University in accordance with the Helsinki declaration.

The clinical information database included sex, CP subtype, gestational age, birth weight, birth asphyxia, neonatal complications [periventricular leukomalacia (PVL), 
hypoxic-ischemic encephalopathy (HIE), and mental retardation $(\mathrm{MR})$ ], and maternal risk factors [premature rupture of membrane (PROM), threatening premature labor (TPL), and pregnancy-induced hypertension (PIH); Table 1]. Diagnosis and classification of CP and diagnosis of birth asphyxia, PVL, HIE, MR, PROM, PIH, and TPL were described previously (Bi et al., 2014).

\section{Selection of SNPs and Genotyping}

Venous blood samples were collected into tubes containing EDTA in the second morning after hospitalization. The samples were centrifuged at $1,500 \times \mathrm{g}$ for $20 \mathrm{~min}$ at $4^{\circ} \mathrm{C}$, and plasma was aliquoted and stored at $-80^{\circ} \mathrm{C}$.

A total of five SNPs (rs510432, rs3804338, rs573775, rs2299863, and rs6568431) of the ATG5 gene were selected from the dbSNP database (http://www.ncbi.nlm.nih.gov/SNP). The

TABLE 1 | Clinical characteristics of all participants.

\begin{tabular}{|c|c|c|c|c|}
\hline \multirow[t]{2}{*}{ Characteristic } & \multicolumn{2}{|c|}{ CP cases } & \multicolumn{2}{|c|}{ Control } \\
\hline & Total (\%) & M/F (n) & Total (\%) & $M / F(n)$ \\
\hline \multicolumn{5}{|l|}{ GESTATIONAL AGE } \\
\hline Preterm (<37 weeks) & $40(5.59)$ & $33 / 7$ & $11(1.67)$ & $10 / 1$ \\
\hline Term ( $\geq 37$ weeks) & $675(94.41)$ & $463 / 212$ & 647 (98.33) & $428 / 219$ \\
\hline Total & $715(100)$ & $496 / 219$ & $658(100)$ & $438 / 220$ \\
\hline \multicolumn{5}{|l|}{ BIRTH WEIGHT } \\
\hline$<2,500 \mathrm{~g}$ & $29(4.06)$ & $20 / 9$ & $17(2.58)$ & $13 / 4$ \\
\hline$\geq 2,500 \mathrm{~g}$ & $686(95.94)$ & $485 / 201$ & 641 (97.42) & $425 / 216$ \\
\hline Total & 715 (100) & $505 / 210$ & $658(100)$ & $438 / 220$ \\
\hline \multicolumn{5}{|l|}{ TYPE OF CP } \\
\hline Spastic CP & 468 (65.45) & $338 / 130$ & - & - \\
\hline Non-spastic CP & 247 (34.55) & $158 / 89$ & - & - \\
\hline Total & $715(100)$ & $496 / 219$ & $658(100)$ & $438 / 220$ \\
\hline \multicolumn{5}{|l|}{ BIRTH ASPHYXIA } \\
\hline Asphyxia & 212 (29.65) & $157 / 55$ & $10(1.52)$ & $7 / 3$ \\
\hline No asphyxia & 503 (70.35) & $339 / 164$ & $648(98.48)$ & $431 / 217$ \\
\hline Total & $715(100)$ & $496 / 219$ & $658(100)$ & $438 / 220$ \\
\hline \multicolumn{5}{|l|}{ COMPLICATION } \\
\hline CP with PVL & $67(9.37)$ & $53 / 14$ & - & - \\
\hline CP without PVL & 648 (90.63) & $445 / 203$ & - & - \\
\hline $\mathrm{CP}$ with $\mathrm{HIE}$ & $96(13.45)$ & $71 / 25$ & - & - \\
\hline $\mathrm{CP}$ without $\mathrm{HIE}$ & 619 (86.55) & 421/198 & - & - \\
\hline $\mathrm{CP}$ with MR & 289 (40.42) & 199/90 & & \\
\hline CP without MR & 426 (59.58) & $297 / 129$ & & \\
\hline \multicolumn{5}{|c|}{ MATERNAL FACTORS } \\
\hline PROM & 68 (9.51) & $51 / 17$ & 24 (3.65) & $16 / 8$ \\
\hline No PROM & 647 (90.49) & $425 / 202$ & $634(96.35)$ & $420 / 214$ \\
\hline TPL & $57(7.97)$ & $40 / 17$ & $33(5.02)$ & $27 / 6$ \\
\hline No TPL & 648 (92.03) & $454 / 196$ & $625(94.98)$ & $411 / 214$ \\
\hline $\mathrm{PIH}$ & $27(3.78)$ & $21 / 6$ & $8(1.22)$ & $7 / 1$ \\
\hline No PIH & 688 (96.22) & $476 / 212$ & 650 (98.78) & $431 / 219$ \\
\hline
\end{tabular}

CP, cerebral palsy; M, male; F, female; PVL, periventricular leukomalacia; PROM, premature rupture of membrane; TPL, threatened premature labor; PIH, pregnancyinduced hypertension. rs510432 SNP is located in the upstream region of the ATG5 gene, while the other four SNPs are located in introns: rs3804338 (2nd), rs573775 (2nd), rs2299863 (7th), and rs6568431 (9th). The minor allele frequencies of these five SNPs in the Chinese Han population are more than 0.05 .

Genomic DNA was isolated from white blood cells using a QIAamp DNA Blood Kit (QIAGEN, USA) according to the manufacturer's instructions. SNPs were genotyped using the Sequenom iPlex MassARRAY platform (Sequenom, San Diego, CA, USA) and blinded to the clinical status of the subjects.

\section{ELISA of Plasma ATG5 Levels}

Before ELISA, frozen samples were removed from the freezer and allowed to reach room temperature $\left(20-25^{\circ} \mathrm{C}\right)$ with gentle mixing. ATG5 levels in the plasma of 58 patients and 56 controls were measured using a Human ATG5 ELISA Kit (Cloud-Clone Corp., USA) according to the manufacturer's protocol. The absorbance at $405 \mathrm{~nm}$ was measured with a SpectraMax 190 Microplate Spectrophotometer (Molecular Devices, USA). The ATG5 level in plasma was normalized to the kit standard, and data were summarized as mean \pm standard error of the mean (SEM).

\section{Statistical Analysis}

For gene analysis, the Hardy-Weinberg equilibrium (HWE), allele and genotype frequencies, odds ratio (OR), 95\% confidence intervals (95\% CI), linkage disequilibrium (LD), and haplotype frequencies were performed using the SHEsis online software platform (http://analysis.bio-x.cn/myAnalysis. php). Discrepancies of genotype and allele frequencies between the patients and controls were compared using the $\chi^{2}$ test. The multiple testing on each individual SNP was corrected using Bonferroni correction. Quantitative results were analyzed using Statistical Product and Service Solutions (SPSS) (version 20.0, SPSS Inc., Chicago, IL, USA). Differences were determined by Student's $t$-test; $P<0.05$ was considered statistically significant.

\section{RESULTS}

\section{Overall Analysis: Allele, Genotype, and Haplotype Frequency of ATG5 Polymorphisms}

Genotype frequencies of the five polymorphisms of ATG5 showed no significant deviations from HWE in controls $(p>0.05$; Table 2). Among all patients with CP and controls, rs6568431 allele and genotype frequencies reached significance $(\mathrm{OR}=1.388$, $95 \%$ CI $=1.173 \sim 1.643, P_{\text {allele }}=0.0005, P_{\text {genotype }}=0.0015$ after Bonferroni correction), and patients with $\mathrm{CP}$ had significantly higher A allele and AA genotype frequencies. These results showed that individuals carrying the rs6568431 AA genotype had a significantly higher risk of CP than those with the CC genotype.

LD of the five SNPs is displayed in Table 3. Owing to the strong LD among four SNPs (rs510432, rs3804338, rs573775, and rs2299863; D’ > 0.9), haplotype analysis was performed revealing all five possible haplotypes (ACCG, ACCT, GCCT, GCTT, and GTCT). The most common haplotypes were GCTT (37.1\%) and 
TABLE 2 | Allele and genotype frequencies of ATG5 genetic variants in CP $(n=715)$ and controls $(n=658)$.

\begin{tabular}{|c|c|c|c|c|c|c|c|c|c|}
\hline & \multicolumn{2}{|c|}{ Allele } & \multirow[t]{2}{*}{$P$} & \multirow{2}{*}{$\begin{array}{c}\text { OR } \\
(95 \% \mathrm{Cl})\end{array}$} & \multicolumn{3}{|c|}{ Genotype } & \multirow[t]{2}{*}{$P$} & \multirow{2}{*}{$\begin{array}{l}\text { Hardy-Weinberg } \\
\text { equilibrium test }\end{array}$} \\
\hline rs510432 & $A$ & $\mathrm{G}$ & & & $\mathrm{A} / \mathrm{A}$ & $A / G$ & $\mathrm{G} / \mathrm{G}$ & & \\
\hline controls & $414(0.407)$ & $602(0.593)$ & 0.285 & $(0.755 \sim 1.086)$ & $88(0.0 .173)$ & $238(0.469)$ & $182(0.358)$ & 0.324 & 0.502 \\
\hline rs3804338 & C & $\mathrm{T}$ & & & $\mathrm{C} / \mathrm{C}$ & $\mathrm{C} / \mathrm{T}$ & $\mathrm{T} / \mathrm{T}$ & & \\
\hline rs573775 & C & $\mathrm{T}$ & & & $\mathrm{C} / \mathrm{C}$ & $\mathrm{C} / \mathrm{T}$ & $\mathrm{T} / \mathrm{T}$ & & \\
\hline $\mathrm{CP}$ & $808(0.650)$ & 436 (0.350) & \multirow{2}{*}{0.477} & 0.940 & $255(0.410)$ & $298(0.479)$ & 69 (0.111) & \multirow{2}{*}{0.316} & 0.192 \\
\hline controls & 747 (0.663) & 379 (0.337) & & $(0.793 \sim 1.114)$ & $251(0.446)$ & $245(0.435)$ & 67 (0.119) & & 0.544 \\
\hline rs2299863 & G & $\mathrm{T}$ & & & $\mathrm{G} / \mathrm{G}$ & $\mathrm{G} / \mathrm{T}$ & $\mathrm{T} / \mathrm{T}$ & & \\
\hline $\mathrm{CP}$ & $79(0.061)$ & $1213(0.939)$ & 0.979 & 0.996 & $4(0.006)$ & 71 (0.110) & $571(0.884)$ & 0.764 & 0.277 \\
\hline
\end{tabular}

$\mathrm{OR}$, odds ratio; $\mathrm{Cl}$, confidence interval.

aAfter Bonferroni correction, the P-value is 0.0005 .

${ }^{b}$ After Bonferroni correction, the P-value is 0.0015 .

TABLE 3 | The linkage disequilibrium among ATG5 SNPS.

\begin{tabular}{lccccc}
\hline $\boldsymbol{D}^{\prime} / \mathbf{r}^{\mathbf{2 a}}$ & rs510432 & rs3804338 & rs573775 & rs2299863 & rs6568431 \\
\hline rs510432 & - & 0.978 & 0.953 & 0.826 & 0.051 \\
rs3804338 & 0.097 & - & 0.982 & 0.928 & 0.217 \\
rs573775 & 0.345 & 0.079 & - & - & - \\
rs2299863 & 0.065 & 0.009 & 0.031 & - & - \\
rs6568431 & 0.002 & 0.014 & $0.010-$ & 0.016 & -
\end{tabular}

a'The standardized D'-values are shown above the diagonal, and the $r^{2}$-values are shown below the diagonal.

ACCT (34.3\%). However, neither the global nor the separate haplotype frequencies showed significant differences between $\mathrm{CP}$ and control groups (data not shown).

\section{Subgroup Analysis}

$\mathrm{CP}$ is a multifactorial and complex disease with various clinical and pathological features. Therefore, a subgroup analysis was performed by sex, clinical subtype, birth asphyxia, PROM, PVL, and HIE. Significant differences in both allele and genotype frequencies of rs6568431 were observed between patients with spastic CP $(n=468)$ and controls $(n=658$; OR $=1.511,95 \%$ $\left.\mathrm{CI}=1.251 \sim 1.824, P_{\text {allele }}=8.50 \mathrm{e}^{-005}, P_{\text {genotype }}=1.57 \mathrm{e}^{-004}\right)$, between patients with spastic quadriplegia $\mathrm{CP}(\mathrm{n}=270)$ and controls $\left(\mathrm{OR}=1.927,95 \% \mathrm{CI}=1.533 \sim 2.421, P_{\text {allele }}=7.35 \mathrm{e}^{-008}\right.$, $P_{\text {genotype }}=3.24 \mathrm{e}^{-009}$; Table 4), and between patients with maternal PROM $(n=68)$ and controls (OR $=2.041,95 \%$ $\left.\mathrm{CI}=1.390 \sim 3.000, P_{\text {allele }}=0.002, P_{\text {genotype }}=0.00004\right)$. The significant difference in allele frequency for rs6568431 between patients with birth asphyxia $(n=212)$ and controls $(P=$ $0.011)$ disappeared after Bonferroni correction. The differences in allele and genotype frequencies were not significant between

CP patients with PVL $(n=67)$ or HIE $(n=96)$ and control subjects for any of the five SNPs of ATG5.

\section{Plasma ATG5 Quantification}

To evaluate the effect of ATG5 on the generation and development of CP, 58 patients with CP and 56 controls were selected from the SNP-tested sample for the plasma ATG5 protein assay by ELISA. Mean plasma ATG5 levels were significantly lower in CP patients than that in controls (cases $=$ $9.471 \pm 0.658 \mathrm{ng} / \mathrm{mL}$, controls $=11.806 \pm 0.785 \mathrm{ng} / \mathrm{mL}, P=$ 0.024, $P<0.05$; Figure 1A). Furthermore, plasma ATG5 levels were different between individuals with the AA genotype and those with the AC+CC genotype of rs6568431 (AA $=6.896 \pm$ $1.076 \mathrm{ng} / \mathrm{mL}, \mathrm{AC}+\mathrm{CC}=10.990 \pm 0.561 \mathrm{ng} / \mathrm{mL}, P=0.026, P<$ 0.05 ; Figure 1B).

\section{DISCUSSION}

The present study is the first to link a genetic variant within the ATG5 gene to CP. We showed that the rs6568431 SNP of the ATG5 gene was associated with CP patients. Between 715 cases and 658 controls, the association was still statistically significant after Bonferroni correction $\left(P_{\text {allele }}=0.0005, P_{\text {genotype }}=0.0015\right)$. Through association analysis between SNPs and subgroups, only rs6568431 was associated with spastic, spastic quadriplegia, and PROM subgroups. The strongest correlation was found in spastic quadriplegia $\mathrm{CP}$, suggesting that ATG5 might have a more important influence in severe types of CP. Furthermore, the observation of lower plasma ATG5 levels in CP patients and in individuals with the AA genotype of rs6568431 indicates that the variant of ATG5 confirmed in CP patients may change the level of Atg5 protein and interfere with the activity of autophagy, thereby acting as a risk factor for $\mathrm{CP}$ onset. 
TABLE 4 | Allele and genotype frequencies of ATG5 genetic variants in spastic CP $(n=468)$ and quadriplegia CP $(n=270)$ and controls $(n=658)$.

\begin{tabular}{|c|c|c|c|c|c|c|c|c|c|}
\hline \multirow[b]{2}{*}{ rs510432 } & \multicolumn{2}{|c|}{ Allele } & \multirow[t]{2}{*}{$P$} & \multirow{2}{*}{$\begin{array}{c}\text { OR } \\
(95 \% \mathrm{Cl})\end{array}$} & \multicolumn{3}{|c|}{ Genotype } & \multirow[t]{2}{*}{$P$} & \multirow{2}{*}{$\begin{array}{l}\text { Hardy-Weinberg } \\
\text { equilibrium test }\end{array}$} \\
\hline & A & $G$ & & & A/A & $A / G$ & $G / G$ & & \\
\hline Quadriplegia CP & $145(0.401)$ & $217(0.599)$ & 0.818 & $0.972(0.761 \sim 1.241)$ & $40(0.221)$ & $65(0.359)$ & $76(0.420)$ & 0.036 & 0.001 \\
\hline controls & $414(0.407)$ & $602(0.593)$ & & & $88(0.173)$ & $238(0.469)$ & $182(0.358)$ & & 0.502 \\
\hline Quadriplegia CP & $427(0.861)$ & $69(0.139)$ & 0.783 & $0.958(0.705 \sim 1.301)$ & $186(0.750)$ & $55(0.222)$ & $7(0.028)$ & 0.348 & 0.243 \\
\hline controls & $982(0.866)$ & $152(0.134)$ & & & $423(0.746)$ & $136(0.240)$ & $8(0.014)$ & & 0.429 \\
\hline rs573775 & C & $\mathrm{T}$ & & & $\mathrm{C} / \mathrm{C}$ & $\mathrm{C} / \mathrm{T}$ & $\mathrm{T} / \mathrm{T}$ & & \\
\hline Spastic CP & $535(0.648)$ & $379(0.337)$ & 0.470 & $0.933(0.772 \sim 1.127)$ & $172(0.416)$ & $191(0.462)$ & $50(0.121)$ & 0.644 & 0.786 \\
\hline Quadriplegia CP & $305(0.646)$ & $167(0.354)$ & 0.508 & $0.927(0.740 \sim 1.161)$ & $102(0.432)$ & $101(0.428)$ & $33(0.140)$ & 0.717 & 0.325 \\
\hline controls & $70(0.061)$ & $1070(0.939)$ & & & $2(0.004)$ & $66(0.116)$ & $502(0.881)$ & & 0.914 \\
\hline rs6568431 & A & C & & & $\mathrm{A} / \mathrm{A}$ & $\mathrm{A} / \mathrm{C}$ & $\mathrm{C} / \mathrm{C}$ & & \\
\hline Spastic CP & $313(0.409)$ & $453(0.591)$ & $1.70 e^{-005 a}$ & $1.511(1.251 \sim 1.824)$ & $78(0.204)$ & $157(0.410)$ & $148(0.386)$ & $3.14 e^{-005 b}$ & 0.003 \\
\hline Quadriplegia CP & $193(0.468)$ & $219(0.532)$ & $1.47 e^{-008 c}$ & $1.927(1.533 \sim 2.421)$ & $60(0.291)$ & $73(0.354)$ & $73(0.354)$ & $6.47 e^{-010 d}$ & $3.52 e^{-005}$ \\
\hline controls & $381(0.314)$ & $833(0.686)$ & & & $63(0.104)$ & $255(0.420)$ & $289(0.476)$ & & 0.548 \\
\hline
\end{tabular}

OR, odds ratio; $\mathrm{Cl}$, confidence interval.

a After Bonferroni correction, the P-value is $8.50 e^{-005}$.

${ }^{b}$ After Bonferroni correction, the $P$ value is $1.57 e^{-004}$

${ }^{c}$ After Bonferroni correction, the $P$-value is $7.35 e^{-008}$.

${ }^{d}$ After Bonferroni correction, the P-value is $3.24 e^{-009}$

Till now, about 35 ATG genes have been confirmed. Their functions are mostly related to autophagosome formation, and are conserved from yeast to humans (Zhou and Zhang, 2012). Associations between ATG SNPs and some diseases have been identified in multiple populations; e.g., the associations between polymorphisms in ATG16L1 with inflammatory Crohn disease (Hampe et al., 2007), palmoplantar pustulosis (Douroudis et al., 2011), and psoriasis vulgaris (Douroudis et al., 2012), as well as polymorphisms in ATG10 with breast cancer (Qin et al., 2013) and Vogt-Koyanagi-Harada syndrome (Zheng et al., 2015). These studies indicate that autophagy has multiple effects in the development of diseases.

A variety of studies have showed that variants of ATG5 gene are related to certain diseases of the immune system and neurodegenerative diseases. Genome-wide association studies of SLE in Chinese Han and European populations reported that the rs6568431 SNP of ATG5 was significantly associated with SLE (Graham et al., 2009; Han et al., 2009). A previous study discussed an association of rs573775 with Behçet's disease (BD) in the Chinese southern Han population, and the TT genotype of rs573775 avoided developing BD (Zheng et al., 2015). Chen et al. (2013) studied genetic variants of the ATG5 gene promoter (e.g., rs510432) in sporadic PD. Until now, no study has shown an association between these SNPs and CP. Our study is the first to focus on the association between SNPs in ATG5 and CP and to show a significant association between ATG5 rs6568431 and CP.
According to our findings, the presence of the rs6568431 A allele of the ATG5 gene significantly increased the risk of CP.

Association of ATG5 with different diseases suggests a pleiotropic role of ATG5 in many physiological processes and a potentially shared pathomechanism underlying these diseases, which include neurodegenerative diseases, autoimmune diseases, and inflammatory diseases. These findings also indicate that a disruption of immunological homeostasis might be implicated in the pathophysiology of CP. The reviewed data showed that immune regulatory cells are potentially involved in the chronicity of inborn brain damage (Lisovska et al., 2016). The genotypephenotype correlations of ATG5 are complicated, and ATG5 could also be related to the variability of cell vulnerability in different tissues at different ages and different environmental factors.

Subgroup analysis based on clinical classification can effectively reduce the effect of phenotypic heterogeneity on association analysis in patients with CP. The present study showed for the first time that the association between the ATG5 polymorphism at rs6568431 and $\mathrm{CP}$ is the strongest in spastic quadriplegia, the most severe type of CP (Caselli et al., 2017). Our results suggest that the correlation between ATG5 variation and $\mathrm{CP}$ is more robust in patients with more serious brain damage and disease phenotype.

To explore the correlation between ATG5 gene variants and ATG5 protein expression, we measured ATG5 levels directly. 

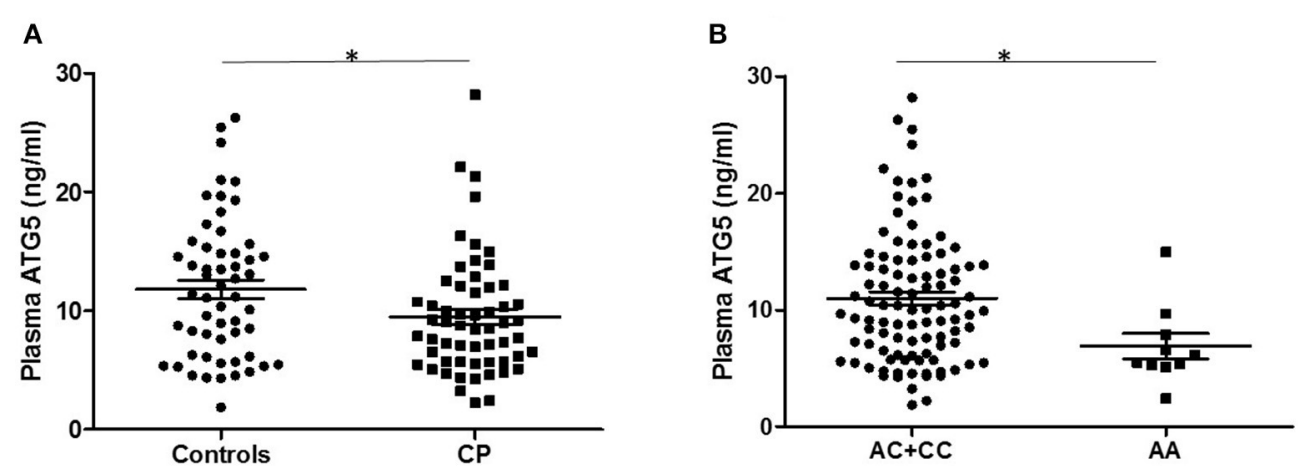

FIGURE 1 | Plasma ATG5 concentrations in patients with controls and CP. (A) Distribution of plasma ATG5 concentrations between all patients with controls (56 participants) and CP (58 patients). (B) Plasma ATG5 levels in individuals carrying different genotypes of rs6568431 (AC+CC = 100, $\mathrm{AA}=10$ ). Each dot represents one individual, and each bar represents the mean value. ${ }^{*} P<0.05$; Student's two-tailed $t$-test; $\mathrm{CP}$, cerebral palsy.

Interestingly, plasma ATG5 levels were lower in patients with CP, and different genotypes of rs6568431 showed different levels of ATG5. This finding is similar to those of BD, in which functional studies showed that the ATG5 gene variant was correlative with ATG5 expression (Zheng et al., 2015). We speculate that genetic variation of ATG5 might change (downregulate) ATG5 protein levels and alter autophagic activities during the pathogenic process of CP. The AA genotype of rs6568431 may be a risk factor of CP, though this needs to be confirmed with a larger sample size.

The contradictory roles of autophagy are often viewed as confusing. In particular, the regulation of autophagy in the nervous system remains largely unknown. Inhibition of autophagy could be a new strategy to prevent ischemic brain injury. Previous studies have shown that the inhibition of autophagy reduces brain damage after cerebral ischemia (Xing et al., 2012; Xie et al., 2016), and during subsequent reperfusion, the protective role of autophagy is probably caused by mitophagy-related mitochondrial clearance and inhibition of downstream apoptosis (Zhang et al., 2013). Furthermore, in vivo studies in mice deficient in Atg5 showed that autophagy may play a protective role against the development of many neurological degenerative diseases. These findings suggest that in the adult brain, ATG5 may function via the autophagy pathway to regulate the survival of neural progenitor cells during their development into new functional neurons (Xi et al., 2016). ATG5-dependent autophagy, which is thought to constantly remove diffuse cytosolic proteins, is very important to prevent abnormal protein accumulation, because these abnormal proteins could disrupt neural function and ultimately lead to neurological degeneration (Hara et al., 2006). In addition, ATG5 may play an important role in preserving axon morphology and membrane structures. Axonal swelling resulting from a lack of ATG5 function is followed by progressive neurodegeneration in mammalian neurons (Nishiyama et al., 2007).

ATG5 may also play an important role at birth, when neonates adapt to the suddenly interrupted trans-placental nutrient supply by inducing autophagy. This is supported by a study showing that amino acid levels in plasma and tissues were reduced and signs of energy depletion were obvious in Atg5-deficient neonatal mice
(Kuma et al., 2004). Our finding that mean plasma ATG5 levels were significantly lower in patients with CP seems to support the conclusions of the above studies, namely that ATG5-dependent autophagy has a protective role against the development of CP. However, it is still unknown if the decreased ATG5 level was due to the feedback inhibition of autophagy activity or not, because previous studies showed that autophagy activity was increased in the acute phase of neonatal brain injury (Ginet et al., 2014; Xie et al., 2016). There is no report yet of autophagy activity in the chronic phase of brain injury such as cerebral palsy. For clarifying this, further investigations monitoring the dynamic changes of autophagy activity in neonatal brain injury are needed.

How the ATG5 gene protects against the development of $\mathrm{CP}$ is still unclear. In the current study, we analyzed five polymorphisms of ATG5 gene in CP patients and ATG5 protein levels in plasma, and found that variants of the ATG5 gene and low levels of ATG5 protein were significantly associated with CP. Our results showed that patients with CP displayed decreased expression of ATG5, which may be associated with fetal or infant brain injury. Thus, we hypothesize that the variant of the ATG5 gene identified in our study may be associated with downregulation of ATG5 protein levels, and the reduced ATG5 protein expression might result in a lower level of autophagosome formation. Therefore, the protective role of ATG5-dependent autophagy against fetal or infant brain injury may weaken and ultimately lead to the development of CP. Moreover, the autophagy-independent functions of ATG5 have been described (Jounai et al., 2007; Zhao et al., 2008; Tal et al., 2009; Zhou and Zhang, 2012; Dipak et al., 2013; Jacqueline et al., 2015); ATG5 may still be involved in the pathogenesis of CP through an autophagy-independent mechanism, despite being an autophagy gene. Further studies are needed to test this hypothesis and examine the role of epigenetic mechanisms of ATG5 in CP.

In conclusion, this study is the first to analyze the association of SNPs in ATG5 and plasma ATG5 levels with the development of $\mathrm{CP}$ in the Chinese population. We found that a variant of the ATG5 gene and low levels of ATG5 protein were significantly 
associated with CP. The variant may affect the expression of ATG5 and alter the activity of autophagy, which may contribute to $\mathrm{CP}$ as a risk factor. ATG5 gene polymorphisms might therefore be related to the development of CP. Additional studies are necessary to further elucidate the biological functions of autophagy in CP and to investigate potential autophagy-related therapy for patients with this disease.

\section{AUTHOR CONTRIBUTIONS}

JX and LX: performed experiments, analyzed data, and wrote the manuscript; DB, JS, and YW: performed experiments and analyzed data; JS, QS, DZ, CM, CG, XZ, YS, and LX: provided samples; JD, XW, and LZ: analyzed the data; CZ and QX: designed the study and revised the manuscript. All authors read and approved the final manuscript.

\section{REFERENCES}

Bi, D., Chen, M., Zhang, X., Wang, H., Xia, L., Shang, Q., et al. (2014). The association between sex-related interleukin-6 gene polymorphisms and the risk for cerebral palsy. J. Neuroinflammation 11, 100-110. doi: 10.1186/1742-2094-11-100

Bi, D., Wang, H., Shang, Q., Xu, Y., Wang, F., Chen, M., et al. (2016). Association of COL4A1 gene polymorphisms with cerebral palsy in a Chinese Han population. Clin. Genet. 90, 149-155. doi: 10.1111/cge.12723

Caselli, T. B., Lomazi, E. A., Montenegro, M. A. S., and Bellomo-Brandão, M. A. (2017). Assessment of nutritional status of children and adolescents with spastic quadriplegic cerebral palsy. Arq. Gastroenterol. 54, 201-205. doi: $10.1590 /$ s0004-2803.201700000-32

Chae, M., Rhee, G. S., Jang, I. S., Kim, K., Lee, J. H., Lee, S. Y., et al. (2009). ATG5 expression induced by MDMA (ecstasy), interferes with neuronal differentiation of neuroblastoma cells. Mol. Cells. 27, 571-575. doi: 10.1007/s10059-009-0075-2

Chen, D., Zhu, C., Wang, X., Feng, X., Pang, S., Huang, W., et al. (2013). A novel and functional variant within the ATG5 gene promoter in sporadic Parkinson's disease. Neurosci. Lett. 538, 49-53. doi: 10.1016/j.neulet.2013.01.044

Colver, A., Fairhurst, C., and Pharoah, P. O. (2014). Cerebral palsy. Lancet 383, 1240-1249. doi: 10.1016/S0140-6736(13)61835-8

De Biase, D., Costagliola, A., Pagano, T. B., Piegari, G., Wojcik, S., Dziewiatkowski, J., et al. (2017). Amyloid precursor protein, lipofuscin accumulation and expression of autophagy markers in aged bovine brain. BMC Vet. Res. 13:102. doi: 10.1186/s12917-017-1028-1

Deretic, V., Saitoh, T., and Akira, S. (2013). Autophagy in infection, inflammation and immunity. Nat. Rev. Immunol. 13, 722-737. doi: 10.1038/nri3532

Dipak, M., Shida, Y., Inès, S., Inti, Z., Aurel, P., Robert, F., et al. (2013). ATG5 is induced by DNA-damaging agents and promotes mitotic catastrophe independent of autophagy. Nat. Commun. 4:2130. doi: 10.1038/ncomms3130

Douroudis, K., Kingo, K., Traks, T., Rätsep, R., Silm, H., Vasar, E., et al. (2011). ATG16L1 gene polymorphisms are associated with palmoplantar pustulosis. Hum. Immunol. 72, 613-615. doi: 10.1016/j.humimm.2011. 03.009

Douroudis, K., Kingo, K., Traks, T., Reimann, E., Raud, K., Rätsep, R., et al. (2012). Polymorphisms in the ATG16L1 gene are associated with psoriasis vulgaris. Acta Derm. Venereol. 92, 85-87. doi: 10.2340/00015555-1183

Fahey, M. C., MacLennan, A. H., Kretzschmar, D., Gecz, J., and Kruer, M. C. (2017). The genetic basis of cerebral palsy. Dev. Med. Child Neurol. 59, 462-469. doi: $10.1111 / \mathrm{dmcn} .13363$

Ginet, V., Pittet, M. P., Rummel, C., Osterheld, M. C., Meuli, R., Clarke, P. G., et al. (2014). Dying neurons in thalamus of asphyxiated term newborns and rats are autophagic. Ann. Neurol. 76, 695-711. doi: 10.1002/ana.24257

Graham, R. R., Hom, G., Ortmann, W., and Behrens, T. W. (2009). Review of recent genome-wide association scans in lupus. J. Intern. Med. 265, 680-688. doi: $10.1111 / j .1365-2796.2009 .02096 . x$

\section{FUNDING}

This work was supported by the Shanghai Municipal Commission of Science and Technology Program (14DJ1400101), the Fourth Round of Shanghai 3-year Action Plan on Public Health Discipline and Talent Program: Women and Children's Health (No. 15GWZK0401), National Key Research and Development Plan for Stem Cell and Transformation Research (2017YFA0104202), the National Natural Science Foundation of China (grants 31611130035, 31371274, 81300556, 81571503, 81771655, U1604165), VINNMER-Marie Curie international qualification (VINNOVA, 2015-04780), the Swedish Medical Research Council (VR 2015-06276), Swedish governmental grants to researchers in the public health service (ALFGBG-429271), and the 973 Projects (2011CB710801).

Hampe, J., Franke, A., Rosenstiel, P., Till, A., Teuber, M., Huse, K., et al. (2007). A genome-wide association scan of nonsynonymous SNPs identifies a susceptibility variant for Crohn disease in ATG16L1. Nat. Genet. 39, 207-211. doi: $10.1038 / \mathrm{ng} 1954$

Han, J. W., Zheng, H. F., Cui, Y., Sun, L. D., Ye, D. Q., Hu, Z., et al. (2009). Genome-wide association study in a Chinese Han population identifies nine new susceptibility loci for systemic lupus erythematosus. Nat. Genet. 41, 1234-1237. doi: 10.1038/ng.472

Hara, T., Nakamura, K., Matsui, M., Yamamoto, A., Nakahara, Y., SuzukiMigishima, R., et al. (2006). Suppression of basal autophagy in neural cells causes neurodegenerative disease in mice. Nature 441, 885-889. doi: $10.1038 /$ nature 04724

Hoare, B. (2014). Rationale for using botulinum toxin A as an adjunct to upper limb rehabilitation in children with cerebral palsy. J. Child Neurol. 29, 1066-1076. doi: 10.1177/0883073814533196

Jacqueline, M. K., Jeremy, P. H., Leslie, A. W., Sunmin, P., Amal, K., Jayanta, D., et al. (2015). Unique role for ATG5 in PMN-mediated immunopathology during M. tuberculosis infection. Nature 528, 565-569. doi: 10.1038/nature16451

Jounai, N., Takeshita, F., Kobiyama, K., Sawano, A., Miyawaki, A., Xin, K. Q., et al. (2007). The Atg5 Atg12 conjugate associates with innate antiviral immune responses. Proc. Natl. Acad. Sci. U.S.A. 104, 14050-14055. doi: $10.1073 /$ pnas.0704014104

Kuma, A., Hatano, M., Matsui, M., Yamamoto, A., Nakaya, H., Yoshimori, T., et al. (2004). The role of autophagy during the early neonatal starvation period. Nature 432, 1032-1036. doi: 10.1038/nature03029

Levine, B., and Kroemer, G. (2008). Autophagy in the pathogenesis of disease. Cell 132, 27-42. doi: 10.1016/j.cell.2007.12.018

Lisovska, N., Daribayev, Z., Lisovskyy, Y., Kussainova, K., Austin, L., and Bulekbayeva, S. (2016). Pathogenesis of cerebral palsy through the prism of immune regulation of nervous tissue homeostasis: literature review. Childs Nerv. Syst. 32, 2111-2117. doi: 10.1007/s00381-016-3245-5

López, P., Alonso-Pérez, E., Rodríguez-Carrio, J., and Suárez, A. (2013). Influence of Atg5 mutation in SLE depends on functional IL-10 genotype. PLoS ONE 8:e78756. doi: 10.1371/journal.pone.0078756

Martin, L. J., Gupta, J., Jyothula, S. S., Kovacic, M. B., Biagini Myers, J. M., Patterson, T. L., et al. (2012). Functional variant in the autophagy-related 5 gene promotor is associated with childhood asthma. PLoS ONE 7:e33454. doi: 10.1371/journal.pone.0033454

McMichael, G., Bainbridge, M. N., Haan, E., Corbett, M., Gardner, A., Thompson, S., et al. (2015). Whole-exome sequencing points to considerable genetic heterogeneity of cerebral palsy. Mol. Psychiatry 20, 176-182. doi: $10.1038 / \mathrm{mp} .2014 .189$

Mizushima, N., Kuma, A., Kobayashi, Y., Yamamoto, A., Matsubae, M., Takao, T., et al. (2003). Mouse Apg16L., a novel WD-repeat protein, targets to the autophagic isolation membrane with the Apg12-Apg5 conjugate. J. Cell Sci. 116, 1679-1688. doi: $10.1242 /$ jcs.00381 
Mizushima, N., Yoshimori, T., and Ohsumi, Y. (2011). The role of Atg proteins in autophagosome formation. Annu. Rev. Cell Dev. Biol. 27, 107-132. doi: 10.1146/annurev-cellbio-092910-154005

Nishiyama, J., Miura, E., Mizushima, N., Watanabe, M., and Yuzaki, M. (2007). Aberrant membranes and double-membrane structures accumulate in the axons of Atg5-null Purkinje cells before neuronal death. Autophagy 3, 591-596. doi: $10.4161 /$ auto.4964

Oppenheim, R. W., Blomgren, K., Ethell, D. W., Koike, M., Komatsu, M., Prevette, D., et al. (2008). Developing postmitotic mammalian neurons in vivo lacking Apaf-1 undergo programmed cell death by a caspase-independent, nonapoptotic pathway involving autophagy. J. Neurosci. 28, 1490-1497. doi: 10.1523/JNEUROSCI.4575-07.2008

Qin, Z., Xue, J., He, Y., Ma, H., Jin, G., Chen, J., et al. (2013). Potentially functional polymorphisms in ATG10 are associated with risk of breast cancer in a Chinese population. Gene 527, 491-495. doi: 10.1016/j.gene.2013.06.067

Shintani, T., and Klionsky, D. J. (2004). Autophagy in health and disease: a double-edged sword. Science 306, 990-995. doi: 10.1126/science.1099993

Tal, M. C., Sasai, M., Lee, H. K., Yordy, B., Shadel, G. S., and Iwasaki, A. (2009). Absence of autophagy results in reactive oxygen species-dependent amplification of RLR signaling. Proc. Natl. Acad. Sci. U.S.A. 106, 2770-2775. doi: $10.1073 /$ pnas.0807694106

Tasdemir, E., Maiuri, M. C., Galluzzi, L., Vitale, I., Djavaheri-Mergny, M., D'Amelio, M., et al. (2008). Regulation of autophagy by cytoplasmic p53. Nat. Cell Biol. 10, 676-687. doi: 10.1038/ncb1730

Tatla, S. K., Sauve, K., Virji-Babul, N., Holsti, L., Butler, C., and Van Der Loos, H. F. (2013). Evidence for outcomes of motivational rehabilitation interventions for children and adolescents with cerebral palsy: an American Academy for Cerebral Palsy and Developmental Medicine Systematic Review. Dev. Med. Child Neurol. 55, 593-601. doi: 10.1111/dmcn.12147

Vázquez, P., Arroba, A. I., Cecconi, F., de la Rosa, E. J., Boya, P., and de Pablo, F. (2012). Atg5 and Ambral differentially modulate neurogenesis in neural stem cells. Autophagy 8, 187-199. doi: 10.4161/auto.8.2.18535

Wang, Y., Zhou, K., Li, T., Xu, Y., Xie, C., Sun, Y., et al. (2017). Inhibition of autophagy prevents irradiation-induced neural stem and progenitor cell death in the juvenile mouse brain. Cell Death Dis. 8:e2694. doi: $10.1038 /$ cddis. 2017.120

Wong, E., and Cuervo, A. M. (2010). Autophagy gone awry in neurodegenerative diseases. Nat. Neurosci. 13, 805-811. doi: 10.1038/nn.2575

Wu, Y. W., Croen, L. A., Vanderwerf, A., Gelfand, A. A., and Torres, A. R. (2011). Candidate genes and risk for CP: a population-based study. Pediatr. Res. 70, 642-646. doi: 10.1203/PDR.0b013e31823240dd
Xi, Y., Dhaliwal, J. S., Ceizar, M., Vaculik, M., Kumar, K. L., and Lagace, D. C. (2016). Knockout of Atg5 delays the maturation and reduces the survival of adult-generated neurons in the hippocampus. Cell Death Dis. 7:e2127. doi: 10.1038/cddis.2015.406

Xie, C., Ginet, V., Sun, Y., Koike, M., Zhou, K., Li, T., et al. (2016). Neuroprotection by selective neuronal deletion of Atg7 in neonatal brain injury. Autophagy 12, 410-423. doi: 10.1080/15548627.2015.1132134

Xing, S., Zhang, Y., Li, J., Zhang, J., Li, Y., Dang, C., et al. (2012). Beclin 1 knockdown inhibits autophagic activation and prevents the secondary neurodegenerative damage in the ipsilateral thalamus following focal cerebral infarction. Autophagy 8, 63-76. doi: 10.4161/auto.8.1.18217

Yeargin-Allsopp, M., Van Naarden Braun, K., Doernberg, N. S., Benedict, R. E., Kirby, R. S., and Durkin, M. S. (2008). Prevalence of cerebral palsy in 8-year-old children in three areas of the United States in 2002: a multisite collaboration. Pediatrics 121, 547-554. doi: 10.1542/peds.2007-1270

Zhang, X., Yan, H., Yuan, Y., Gao, J., Shen, Z., Cheng, Y., et al. (2013). Cerebral ischemia-reperfusion-induced autophagy protects against neuronal injury by mitochondrial clearance. Autophagy 9, 1321-1333. doi: 10.4161/auto.25132

Zhao, Z., Fux, B., Goodwin, M., Dunay, I. R., Strong, D., Miller, B. C., et al. (2008). Autophagosome-independent essential function for the autophagy protein Atg5 in cellular immunity to intracellular pathogens. Cell Host Microbe 4, 458-469. doi: 10.1016/j.chom.2008.10.003

Zheng, M., Yu, H., Zhang, L., Li, H., Liu, Y., Kijlstra, A., et al. (2015). Association of ATG5 gene polymorphisms with Behçet's disease and ATG10 gene polymorphisms with VKH syndrome in a Chinese han population. Invest. Ophthalmol. Vis. Sci. 56, 8280-8287. doi: 10.1167/iovs.15-18035

Zhou, X. J., and Zhang, H. (2012). Autophagy in immunity: implications in etiology of autoimmune/autoinflammatory diseases. Autophagy 8, 1286-1299. doi: $10.4161 /$ auto. 21212

Conflict of Interest Statement: The authors declare that the research was conducted in the absence of any commercial or financial relationships that could be construed as a potential conflict of interest.

Copyright (C) 2017 Xu, Xia, Shang, Du, Zhu, Wang, Bi, Song, Ma, Gao, Zhang, Sun, Zhu, Wang, Zhu and Xing. This is an open-access article distributed under the terms of the Creative Commons Attribution License (CC BY). The use, distribution or reproduction in other forums is permitted, provided the original author(s) or licensor are credited and that the original publication in this journal is cited, in accordance with accepted academic practice. No use, distribution or reproduction is permitted which does not comply with these terms. 